\title{
O TEATRO PEDAGÓGICO DE BRECHT 1
}

\author{
EL TEATRO PEDAGOGICO DE \\ BRECHT
}

\section{THE BRECHT PEDAGOGICAL THEATER}

\author{
Eliete Fernandes Matias ${ }^{2}$
}

\begin{abstract}
RESUMO
Este artigo é uma reflexão sobre a importância das peças didáticas de Brecht no contexto educacional, sendo um gênero teatral que apresenta eventos sociais em seu processo dialético, mostrando o homem como um agente de transformação do mundo, por isso torna-se essencialmente pedagógico. Também por trás de sua forma há a ideia de que os sujeitos são levados a mudar suas atitudes diante das adversidades quando conhecem seu papel social.
\end{abstract}

PALAVRAS- CHAVE: Teatro. Peças didáticas. Ação cênica.

\section{RESUMEN}

Este artículo es una reflexión sobre la importancia de las piezas didácticas de Brecht en el contexto educativo, siendo un género teatral que muestra eventos sociales en su proceso dialéctico, mostrando al hombre como un agente de transformación del mundo, por lo que se vuelve esencialmente pedagógico. También detrás de su camino se encuentra la idea de que los sujetos cambien sus actitudes frente a la adversidad cuando conocen a su función social.

PALABRAS CLAVE: Teatro. Piezas de enseñanza. Acción escénica.

\begin{abstract}
This article is a reflection on the importance of the pedagogical pieces of Brecht in the educational context, being a theatrical genre that presents social events in its dialectical process, showing the man as an agent of transformation of the world, therefore it becomes essentially pedagogical. Also behind its shape is the idea that subjects are led to change their attitudes in the face of adversity when they know their social role.
\end{abstract}

KEYWORDS: Theater, Teaching pieces. Scenic action.

\footnotetext{
${ }^{1}$ Texto apresentado para aprovação na disciplina História e historiografia do teatro no Mestrado PROFARTES/UFPB no ano de 2015.

${ }^{2}$ Graduada em Artes Cênicas pela Universidade Federal da Paraíba - UFPB; Mestra em Artes pela UFPB (2016); Professora-Colaboradora do Polo UAB da UFPB/Virtual; E-mail. elietefmatias@gmail.com;: Pesquisadora na linha de Pesquisa Ator e Cena: processos, poéticas e metodologias, do Grupo Teatro Tradição e Contemporaneidade, registrado no CNPq.
} 


\section{Brecht: a Arte como luta política, o Teatro como agente de transformação}

"A filosofia que orientou Brecht nas mudanças que ele introduziu no jogo do teatro é a filosofia marxista." (Althusser, 1968, p.54).

No texto Sobre Brecht e Marx 1968, Althusser traça um paralelo entre o que ele denomina de "a revolução de Brecht no teatro" e "a revolução de Marx na filosofia”, porque eles não se contentaram em interpretar o mundo, precisaram transformá-lo.

A escrita deste texto por Althusser é, sem dúvida; uma importante constatação e reconhecimento para uma obra rica em diversidade e até hoje insuperável em qualidade estética e política.

Brecht não elabora todas as partes de um novo teatro, seja um antiteatro, seja um teatro que rompe com todo o teatro passado, que, por exemplo, suprime todo o repertório. Do mesmo modo, Marx e os marxistas não elaboram todas as partes de uma nova filosofia, uma antifilosofia, ou uma filosofia que rompe com toda a tradição filosófica passada. Brecht toma o teatro tal como ele existe, e opera no interior do teatro tal como ele existe. Do mesmo modo, Marx toma a filosofia tal como ela existe, e opera no interior da filosofia tal como ela existe. O que Brecht revoluciona é a maneira de praticar o teatro: o que ele traz de novo é uma nova prática do teatro. Do mesmo modo, o que Marx revoluciona na filosofia, é a maneira de praticar a filosofia: o que ele traz de novo é uma nova prática da filosofia [...]. (Althusser, 1968, p.55)

Uma das principais contribuições de Brecht para o teatro foi criar recursos teatrais diferenciados, ao mesmo tempo, estéticos e políticos, buscando elementos diferentes dos usados no teatro dramático que conduzia o público a emoção e a ilusão, nunca a uma reflexão social.

Na obra de Brecht observamos uma nova forma de fazer teatral, por ser um teatro essencialmente político, reflexivo e que coloca a arte como agente de transformação. Seu trabalho como artista concentrou-se, especialmente, na crítica ao desenvolvimento das relações desumanizadas no sistema capitalista. Também denunciou o uso da arte para fortalecer a dominação da elite e propôs uma revolução estética.

Ernest Fischer (1983.p.15) em sua obra A necessidade da Arte, define a percepção de Brecht sobre a função da arte na sociedade: "Bertolt Brecht afirma que o efeito da arte para a classe dominante é esconder a luta de classes pela afirmação de uma universalidade da obra de arte. Para Brecht, o que a arte deve é justamente enfatizar a luta de classes e incitá-la”. 
Fischer indica a relação marcante que existe na obra de Brecht entre arte, sociedade e luta de classes. Entre as expressões artísticas, foi no teatro que Brecht se debruçou com tenacidade, por compreender o potencial transformador presente na arte de representar.

As artes cênicas como forma de expressão humana presente em todas as culturas em suas manifestações mais primordiais, proporcionam uma vasta gama de possibilidades expressivas, por reunir num mesmo espaço/tempo várias linguagens artísticas, simbólicas e comunicativas. Kowzan (2006, p.97) afirma que: "A arte do espetáculo é, entre todas as artes e, talvez, entre todos os domínios da atividade humana, aquela onde o signo manifesta-se com maior riqueza, variedade e densidade”. Assim, compreendemos que a construção de um corpo expressivo e comunicativo na metodologia de Brecht é mais do que simples gesticulação, um 'gestus' imprime uma qualidade social a aquele que o executa, como bem explica Koudela:

Um homem que vende peixe mostra, entre outras coisas, o gestus de vender. Um homem que escreve seu testamento, uma mulher que atrai um homem, um policial que espanca um homem, um homem que faz o pagamento a dez homens- em tudo isso está contido o gestus social (BRECHT apud KOUDELA, 2007, p. 101).

A obra de Brecht como dramaturgo, poeta e encenador está repleta de mensagens que nos levam a uma profunda reflexão sobre as relações sociais e o papel da arte como instrumento para questionamentos e entendimento dessas relações. Ao longo da vida, escreveu centenas de poemas, porém no que mais se destacou foi na produção teatral, principalmente com a sua proposta de encenação 'quebrando a ilusão do palco' e propondo um diálogo entre atores e plateia.

Eugen Berthold Friedrich Brecht, mais conhecido como Bertolt Brecht, teve uma vida conturbada, apesar de nascer em família burguesa enfrentou grandes dificuldades. Como está relatado em sua biografia, Brecht viveu as duas grandes guerras mundiais, os horrores e tragédias provocados por esses dois acontecimentos históricos e sofreu na pele as perseguições nazistas, tendo que fugir da Alemanha (seu país) para não ser assassinado por causa de seus ideais políticos. Com certeza esses fatores moldaram o 
fazer teatral e literário desse célebre dramaturgo e poeta.

Em todos os gêneros que escreveu, Brecht deixou sua marca de contestador do sistema político, econômico e social opressor. Suas ideias nos leva a uma profunda reflexão sobre as relações sociais e o papel da arte enquanto ferramenta posta a serviço das classes dominantes, ou usada como instrumento libertário.

Do ponto de vista pedagógico, as peças de Brecht assinalam para um caminho de entendimento do indivíduo de seu papel social, partindo dos conceitos do materialismo dialético numa visão Marxista de pensar a realidade em constante mudança por meio de pensamentos contrários que dão origem a um terceiro, que os harmoniza. De acordo com Koudela:

A teoria de ensino-aprendizagem de Brecht é uma pedagogia dialética, que combina elementos indutivos e dedutivos na aprendizagem, colocando à nossa disposição um método de exame e ação sobre a realidade social. Seu conceito de peça didática pretende ensinar a "alegria da libertação" e tornar apreensível o ato de liberdade (KOUDELA, 1992, p. 12).

Percebemos essa ideologia na obra de Brecht por estar sempre apresentando o homem como agente de transformação do mundo, pela tomada de consciência e pela necessidade de empoderamento e questionamento diante das convenções sociais.

Para Brecht, o jogo teatral pode ser usado de forma pedagógica para o homem pode mudar de atitude diante das adversidades e promover as mudanças necessárias à harmonia social. "[...] Os homens contemporâneos se interessam por situações e acontecimentos em relação aos quais eles possam fazer alguma coisa." (BRECHT, 1967, p. 282).

Toda a sua obra nos inspira a refletir a função do teatro na sociedade, percebendo a força da dramaturgia em oposição aos ditames de um regime capitalista pouco preocupado com o humanismo e contribuinte com a implantação de uma desigualdade social crescente no mundo.

Neste sentido este estudo busca de forma simples abordar a relevância da obra de Brecht, como ponto de partida para a prática do teatro educativo. Para tanto, perseguimos o pressuposto de que Brecht propõe um teatro que parte da simplicidade do gesto e do minimalismo para compor a 
ação teatral, que de tal forma não necessita de grandes arquiteturas para acontecer, estando posta em qualquer lugar que possamos chamar de palco.

Seu teatro didático se presta a nos conduzir ao exercício de uma reflexão sobre os paradigmas sociais, sendo um teatro que parte do jogo e não tem objetivos espetaculares, servindo como experiências estéticas sempre voltadas ao social, adequando-se aos objetivos educacionais.

\section{O rádio e as peças didáticas}

Em seu tempo Brecht viu o surgimento do rádio como uma mídia importantíssima para disseminar informações e formar opinião entre os ouvintes. De pronto imaginou esse meio de comunicação como um instrumento a ser utilizado pelos artistas de forma educativa e democrática, para isso produziu peças radiofônicas como no ano de 1928 a peça didática "Um voo sobre o oceano" um épico sobre a primeira travessia aérea do Atlântico realizada por Charles Lindbergh em 1927. Nesta peça Brecht usa da metáfora da luta do homem com os elementos da natureza para expressar a busca humana por mudanças e superação. De forma inusitada ele coloca o rádio como elemento central no debate.

Outras obras de Brecht para o rádio que se destacaram são: Ascensão e Queda da Cidade de Mahagonny, O Julgamento de Lucullus, um ataque frontal ao crescente militarismo nazista, e A Ópera dos Três Vinténs que se tornaria o grande sucesso musical dos anos 20 .

Ele compreendia que o rádio teria que caminhar lado a lado com o novo teatro, propondo transformá-lo, de mero veículo de difusão que pressupõe os ouvintes como receptores passivos, a um interativo canal de comunicação ao qual todos tivessem acesso. Acreditava que o rádio poderia ser uma mídia atuante como instrumento de transformação e revolução social.

O jovem Brecht acreditava no potencial sócio - político - ideológico do rádio e temia que esse passasse a ser apenas mais um meio de disseminação do ideário das classes dominantes, o que fatalmente ocorreu. 
Em sua utopia radiofônica Brecht afirma:

A radiodifusão poderia ser transformada de aparelho de distribuição em aparelho de comunicação. Poderia ser o mais fantástico meio de comunicação imaginável na vida pública, um imenso sistema de canalização. Quer dizer: isto se não somente fosse capaz de emitir, como também de receber; em outras palavras, se conseguisse que o ouvinte não se limitasse a escutar, mas também falasse, não ficasse isolado, mas relacionado. (Brecht 1993, p.15).

Mesmo hoje com o advento das novas tecnologias o rádio ainda exerce um fascínio nas pessoas sendo revivido pelos jovens nas rádios virtuais. Mas, infelizmente, sua difusão de maior alcance encontra-se nas mãos de grandes grupos financeiros e segue o destino de todos os veículos de comunicação de massa, sendo instrumento de controle social a partir da ideologia dominante, como previu Brecht.

\section{A pedagogia do teatro de Brecht}

A concepção de uma pedagogia teatral em Brecht surge num momento crítico na sociedade da Alemanha pós-primeira guerra mundial. Esclarecendo que o foco das peças didáticas são os jovens, que na utopia desse dramaturgo, poderiam a partir de uma pedagogia estética buscar a transformação da sociedade em um espaço mais justo e igualitário. Assim em suas peças didáticas ele nos apresenta perguntas, levando-nos a indagar mais e mais a partir da linha traçada pelo texto e pela ideia que se materializa em ação dramática. Isso nos remete a afirmativa de Fayga Ostrower (1993):

Em todas as matérias com que o homem lida se fará sentir sua ação simbólica. Em todas as linguagens, ao articular uma matéria, o homem deixa a sua marca, simboliza e indaga, movido por sua pergunta ulterior, que é pelo sentido de viver. Rearticulada, a matéria retorna ao homem. Na forma configurada, cada pergunta encerra uma resposta. (Ostrower, 1985, p. 51)

Verifica-se que a pedagogia proposta por Brecht através das peças didáticas, pressupõe o diálogo reflexivo da realidade vivida pelos jogadores que se revezam entre líderes e liderados, estando livres para proporem 
mudanças e transpor obstáculos.

As peças didáticas são um conjunto específico de produções dentro da escrita brechtiana, sendo possível diferenciá-las das peças épicas pelo seu caráter não espetacular. Assim, essa produção dramatúrgica de Brecht é menos conhecida que as peças épicas de espetáculos, tanto pelo menor volume de textos, quanto pela quantidade de apreciação.

A partir de estudos sobre o sentido da obra brechtiana para uma prática educacional e motivados por suas peças didáticas, contemplamos as possibilidades de um teatro que não necessita da presença do espectador para acontecer, pois se trata de uma ação participativa, com espaço para a improvisação que se adequa ao ambiente escolar.

Nas peças didáticas brechtianas, ocorre um revezamento entre atuar e assistir, trazendo a ideia de educação dos jovens tanto para produzir como para apreciar espetáculos teatrais.

É certamente uma proposta que parte da estética, mas só se concretiza através do posicionamento político, social e cultural dos participantes. Nesse ponto concorda-se com Koudela (1992, p.13) quando afirma: "A pedagogia brechtiana se constitui como uma pedagogia ou educação política, na medida em que adere a um projeto histórico- filosófico e a uma teoria social".

As peças didáticas não são um roteiro para encenação, elas dão aos participantes a oportunidade da construção estética do fazer teatral, proporcionando ao aluno a chance de ser parte atuante das ações dramáticas, como aponta o próprio Brecht (2005):

Necessitamos de um teatro que não nos proporcione somente as sensações, as ideias e os impulsos que são permitidos pelo respectivo contexto histórico das relações humanas (...) mas, sim, que empregue e suscite pensamentos e sentimentos que desempenhem um papel na modificação desse contexto. (Brecht, 2005, p.14).

Portanto, a partir dessa ideia a pedagogia de Brecht coloca o fazer teatral possível a qualquer um, atores e não atores que desejem vivenciar uma experiência estética a partir do jogo teatral e das peças didáticas.

Nessa linha de pensamento compreendemos que esse processo de 
ação teatral envolve o gesto e as atitudes significativas no contexto social, sendo o jogo teatral o elemento fundamental na aquisição do conhecimento e da autonomia dos participantes, como ressalta Koudela (1992, p.13).

O modelo de ação que é proposto por Brecht em seu teatro, como uma ferramenta didática, amplia o sentido da palavra que passa a figurar como algo em construção, compreendendo o texto como um modelo que sofre uma ação por estar aberto ao experimento. Outro elemento importante é o ‘estranhamento' que se propõe ao quebrar os condicionamentos de atitudes e hábitos, levando o participante a refletir criticamente o seu momento histórico-social e político relacionando ao tema central da peça didática.

Essa preocupação é extremamente forte numa época em que Brecht estava particularmente preocupado com o alcance didático de seu trabalho e procurava, por meio de considerações de âmbito filosófico-científico, incorporar o problema da luta de classes à sua produção. (GATTI, 2008, p.54)

Há muito os professores de teatro buscam formas concretas de levar a cabo o ensino relacionado ao teatro educação, e na maioria dos projetos encontram-se os fundamentos das peças didáticas de Brecht. Apesar do tempo, suas propostas ainda são atuais e adequadas ao trabalho com jovens em escolas, sindicatos e associações.

Concluímos que ainda há uma forte influência da fase didática de Brecht nos métodos de ensino em teatro. Sendo importante por suas dimensões sociais e pedagógicas que provocam o debate e a experimentação de formas e visões variadas e por possibilitar a reformulação da maneira de pensar e agir diante de questões envolvendo temas sociais tais como: degradação ambiental, desigualdade social, temas relacionados à saúde, exploração do homem pelo homem, entre outros.

Brecht nos deixa a ideia do potencial emancipatório que o Teatro pode propiciar aos participantes. Corroborando com sua a ideia de que a realização do homem não depende apenas da harmonia de sua vida interior, mas do modo como este se insere no contexto social, numa consonância entre valores individuais e coletivos que propiciem a superação das desigualdades. Em Brecht o caminho para isso seria através de uma educação estética e política. 


\section{REFERÊNCIAS}

ALTHUSSER, Louis. Sobre Brecht e Marx (1968). Crítica Marxista, São Paulo, Ed.Revan, v.1, n.24, 2007, p.51-62.

BRECHT, Bertold. Estudos sobre teatro. Rio de Janeiro: Nova Fronteira, 2005.

. Teoria de la rádio (1927-1932). In: BASSETS, L. (edt). De las ondas rojas a las rádios libres. Barcelona: G. Gilli, 1998.

. The Radio as an Apparatus of Communication in

STRAUSS, Neil (org.). Radiotext (e). New York, Semiotext (e), 1993u.

FISCHER, Ernst. A Necessidade da Arte. Rio de Janeiro: Zahar, 1983.

- Teatro dialético: ensaios. Rio de Janeiro: Civilização

Brasileira, 1967.

GATTI, Luciano. Benjamin e Brecht: a pedagogia do gesto. Cadernos de Filosofia Alemã no 12 - p. 51-78 - jul.-dez. 2008.

KOUDELA, Ingrid Dormien. Brecht: um jogo de aprendizagem. São Paulo: Perspectiva, 2007.

. Texto e Jogo - uma didática brechtiana. São Paulo: Perspectiva, 1996.

. Um Voo Brechtiano. São Paulo: Perspectiva, 1992.

KOWZAN, Tadeusz. Os signos no teatro: introdução à semiologia da arte do espetáculo. In: GUINSBURG, Jacó; Coelho Netto, José Teixeira; Cardoso, Reni Chaves (org.). Semiologia do teatro. São Paulo: Perspectiva, 2006, p. 93-123.

OSTROWER, Fayga. Criatividade e processos de criação. 9 ed. Petrópolis: Vozes, 1993. 187 p. Ilus.

Recebido em agosto de 2018.

Aprovado em outubro de 2018.

Publicado em dezembro de 2018. 